\title{
Male Hatano High-Avoidance Rats Show High Avoidance and High Anxiety-Like Behaviors as Compared with Male Low-Avoidance Rats
}

\author{
Yasuyuki HORII ${ }^{1,2)}$, Maiko KAWAGUCHI ${ }^{3,4)}$, Ryo OHTA ${ }^{5)}$, Akihiro HIRANO ${ }^{3,4)}$, \\ Gen WATANABE ${ }^{1,2)}$, Nobumasa KATO ${ }^{6,7)}$, Toshiyuki HIMI ${ }^{4)}$ and Kazuyoshi TAYA ${ }^{1,2}$ ) \\ 1) Department of Basic Veterinary Science, United Graduate School of Veterinary Sciences, Gifu University, 1-1 \\ Yanagido, Gifu, Gifu 501-1193, Japan \\ ${ }^{2)}$ Laboratory of Veterinary Physiology, Tokyo University of Agriculture and Technology, 3-5-8 Saiwaicho, Fuchu, \\ Tokyo 183-8509, Japan \\ ${ }^{3)}$ School of Agriculture, Meiji University, 1-1-1 Higashimita, Tama-ku, Kawasaki, Kanagawa 214-8571, Japan \\ ${ }^{4)}$ Faculty of Pharmacy and Research Institute of Pharmaceutical Science, Musashino University, 1-1-20 Shinmachi, \\ Nishi-Tokyo, Tokyo 202-8585, Japan \\ 5) Division of Toxicology, Hatano Research Institute, Food and Drug Safety Center, 729-5 Ochiai, Hadano, \\ Kanagawa 257-8523, Japan \\ ${ }^{6)}$ Department of Psychiatry, Showa University School of Medicine, 6-11-11 Kita-Karasuyama, Setagaya-ku, Tokyo \\ 157-8577, Japan \\ 7) JST, CREST
}

\begin{abstract}
Our prime objective was to establish an optimal model animal for studying avoidance learning and memory in rodents. The two-way rat inbred strains of Hatano high- (HAA) and lowavoidance (LAA) animals were originally selected and bred in accordance with their high or low performance respectively in the shuttle-box active avoidance task. Previous studies demonstrated that they have clear strain differences in endocrine stress response, which is related to acquisition of aversive learning and emotional reactivity. To evaluate the effect of selection by the shuttle-box task on avoidance performance and emotional reactivity, male Hatano rats underwent passive avoidance, open field and elevated plus maze tests. The present results show that the avoidance performance in the passive task was significantly greater in HAA rats than in LAA rats. Furthermore, HAA rats showed high anxiety-like behaviors compared with LAA rats in open field and elevated plus maze tests. Taken together, this study demonstrated that 1) selection and breeding of Hatano HAA and LAA strain rats by shuttle-box task had been properly carried out with the criterion of high and low avoidance performance respectively and that 2) HAA rats were predisposed to high anxiety compared with LAA rats. These results indicated that Hatano HAA and LAA rats can be useful models for studying avoidance learning and memory.
\end{abstract}

Key words: anxiety, elevated plus maze test, hatano rats, learning and memory, passive avoidance task

\section{Introduction}

The prime objective in the present study was to establish an optimal model for studying avoidance learning and memory in rodents. For a prey like the rodents, un- derstanding and avoiding aversive situations is very essential to their survival and to conserve the species. Thus, emotionality, especially anxiety and fearfulness, could be an important factor in exhibiting defensive reactions and learning and memorizing aversive situations [14]. 
Animals have their own species-specific defensive reactions (SSDRs) in nature, such as escape, freezing, attacking and defensive burying behaviors in rats [14]. In the laboratory, there are 2 major behavioral paradigms of avoidance learning tasks in rats, such as active and passive avoidance tasks $[22,30]$. For the shuttle-box active avoidance task [30], an animal is first given light and buzzer alarms as condition stimuli (CS) and continuously given foot shocks as unconditioned stimuli (US). Animals that have learned about the CS begin to flee to an adjacent non-stress chamber before they receive US or begin to freeze in place without US, but animals that have not learned about CS flee to the nonstress chamber after receiving US or begin to freeze in place with US. Thus, freezing rats might show low avoidance rates regardless of CS learning in the active task. For the step-through type passive avoidance task [22], the apparatus consisted of 2 chambers, light and dark boxes. Once an animal is placed in the light box, it quickly moves to dark box because rodents prefer darker places in nature. In the dark box, the animal is given an unavoidable foot shock as a learning session. After few minutes, $24 \mathrm{~h}$, several days or more, the same procedure is repeated and the latency in entering the dark box is recorded as memory retention. As moving or staying allows the animal to avoid US, it is called an active or passive avoidance task, respectively.

Hatano high- (HAA) and low-avoidance (LAA) animals that were derived from Sprague-Dawley (SD) rats (Charles River Laboratories Japan, Inc., Kanagawa, Japan) were selectively bred on the basis of high or low avoidance rates respectively in the shuttle-box active avoidance task [30]. For the selection of Hatano rats, 48 SD rats (24 males and 24 females) were used as the first parental population. The male and female SD rats showing the highest or lowest avoidance responses during 4 daily sessions of 60 trials were selected and mated with each other as HAA or LAA, respectively. For LAA, noteworthy animals showing freezing behavior were removed at every generation [31] because it might be included CS learning animal but showing low avoidance performance as mentioned above. Selection by shuttlebox task was similarly applied for more than 20 generations, and HAA and LAA were maintained through full sib-mating for more than 60 generations since 1985 . Remarkably, the avoidance response in the shuttle-box task might not be only due to the CS learning but might also be due to the cumulative effect of other factors such as locomotor activity, emotionality and response to stress [7, 10-12, 35]. Indeed, some other shuttle-box two-way selective inbred rats showed a discrepancy in the results of the passive avoidance paradigm [8-10, 15, 16]. Thus, testing avoidance performance in a manner other than the shuttle-box task is also required to firmly demonstrate the utility of Hatano rats in studying avoidance learning and memory. Moreover, our previous reports demonstrated that HAA and LAA have strain differences in locomotor activity and endocrine stress response [2-4, $21,28,31]$. In brief, HAA shows high activity in running wheel cage [28], high adrenocorticotropin (ACTH) and low prolactin in plasma during restraint stress compared with LAA [2, 4]. But emotional characteristics of Hatano rats have not been investigated yet.

Furthermore, it is known that the performance of passive avoidance is higher in adolescents (180 days old) or adults (365 days old) than in juveniles (30 days old) or old rats (547 days old) [27]; also, juvenile male rats show high and well-rounded activity in open field and elevated plus maze tests, respectively, as compared with the other developmental stages $[19,26]$. Thus, in the present study, adolescent and juvenile male Hatano rats were investigated for their avoidance learning by passive avoidance task and for anxiety-like behaviors by open field and elevated plus maze tests, respectively, to evaluate the effects of selection by the shuttle-box task on avoidance performance and emotional reactivity.

\section{Materials and Methods}

\section{Animals}

HAA rats from the 62nd generation and LAA rats from the 60th generation produced at Hatano Research Institute were used in the present study. The animals were transported to Musashino University after weaning and kept under standard ambient lighting (0700-1900 h), room temperature $\left(22.5 \pm 0.5^{\circ} \mathrm{C}\right)$ and humidity conditions $(55 \pm 10 \%)$ and had ad libitum access to food (CE2, CLEA Japan, Inc., Tokyo, Japan) and water. All behavioral tests were performed during 0900 to $1600 \mathrm{~h}$, and the same animals were used for all behavioral tests. All experimental procedures used in this study were in accordance with the guidelines of the Animal Care and Use Committee of Musashino University and the Hatano Research Institute of the Food and Drug Safety Center. 


\section{Passive avoidance task}

Fourteen-week-old HAA and LAA rats underwent passive avoidance test as described previously [22]. A step-through type passive avoidance test unit (PA-3001, O'Hara \& Co., Tokyo, Japan) comprised of a bright and dark compartment was used. A guillotine door separated the compartments. The passive avoidance test consisted of two sessions. In the first session, each rat was placed in the bright compartment. When it spontaneously moved into the dark compartment, it was given an electric shock ( $50 \mathrm{~V}$ for $20 \mathrm{~s}$ ) through the floor grid. The guillotine door was set to close upon transfer, subjecting the rat to the full duration of the electric shock. Infrared sensors monitored the transfer from the bright to dark compartment, which was recorded as the transfer latency time in seconds. The second session was carried out $24 \mathrm{~h}$ after the first session. The transfer latency time was recorded in the second session as the operational measure of the effectiveness of the test. For each group, the number of rats not entering the dark compartment during a period of $300 \mathrm{~s}$ was recorded as the no transfer response. The apparatus was cleaned with a $70 \%$ ethanol solution between the tests.

\section{Open field test}

Five-week-old HAA and LAA rats underwent circular open field test. Each rat was placed in the open field (OF-25R, $750 \mathrm{~mm}$ diameter, $400 \mathrm{~mm}$ high, Muromachi Kikai, Tokyo, Japan) and allowed to explore the field freely for $5 \mathrm{~min}$. Horizontal activity was recorded using a movie camera and was measured by CompACT VAS for Windows circular open field version 3.13 behavioral analysis software (Muromachi Kikai, Tokyo, Japan). The total time traveled, total distance traveled, and total time exploring the central area were recorded. The apparatus was cleaned with a $70 \%$ ethanol solution between the tests.

\section{Elevated plus maze test}

Two days after the open field test, 5-week-old HAA and LAA rats underwent an elevated plus maze test. The elevated plus maze (EPM-04R, Muromachi Kikai, Tokyo, Japan) consisted of 2 open arms and 2 enclosed arms that merge at a central platform to form a plus shape. The entire apparatus was elevated to a height of $50 \mathrm{~cm}$ above the floor. Each rat was placed on the common central platform, and its horizontal activity in the maze was then monitored for 5 min using the CompACT
VAS for Windows Elevated Plus Maze version 3.11 video tracking system (Muromachi Kikai, Tokyo, Japan). The number of open-arm entries and the time spent in the open- or closed-arm were recorded. The percentage of time spent in open arms was calculated by the formula (time spent in open arms/sum of the time spent in open and closed arms) $\times 100$. The apparatus was cleaned with a $70 \%$ ethanol solution between the tests. Any animals that fell off of the apparatus were removed from the data analysis.

\section{Statistical analysis}

All results were expressed as means \pm standard error of the mean (SEM). For the open field and elevated plus maze tests and the latency time in the first session of passive avoidance task, the independent $t$-test was applied to comparisons between HAA and LAA rats using root square conversion of data. Kaplan-Meier survival analysis followed by a log-rank comparison test was applied for the passive avoidance task. Statistical differences were considered significant when the $P$ value was less than 0.05 . Independent $t$-tests were performed using SPSS for windows version 18.0 (Chicago, IL, USA), and the survival analysis with a log-rank comparison test was performed using StatView 5.0J software for Windows (SAS Inc., Cary, NC, USA).

\section{Results}

\section{Passive avoidance task}

There was no significant strain difference in latency time in the first session between HAA $(8.0 \pm 1.2, \mathrm{n}=10)$ and LAA rats $(15.0 \pm 3.3, \mathrm{n}=10)$. The survival analysis in the second session demonstrated a significant difference in performance between HAA and LAA rats in the passive avoidance task. The stay duration in the bright compartment in the second session was significantly longer in HAA (median value, $241 \mathrm{~s}$; top 25\%, $137 \mathrm{~s}$; top $75 \%$, not available; $n=10$ ) than in LAA rats (median value, $30 \mathrm{~s}$; top $25 \%, 13 \mathrm{~s}$; top $75 \%, 81 \mathrm{~s}, \mathrm{n}=10$ ) (Fig. 1).

\section{Open field test}

The total time traveled by HAA rats in the open field test was significantly longer than that by LAA rats (HAA, $80.50 \pm 4.32 \mathrm{~s}, \mathrm{n}=10$; LAA, $65.44 \pm 3.63 \mathrm{~s}, \mathrm{n}=10$ ) (Fig. 2A). In addition, HAA rats traveled significantly longer distance as compared with LAA rats (HAA, $17.95 \pm 1.08$ 


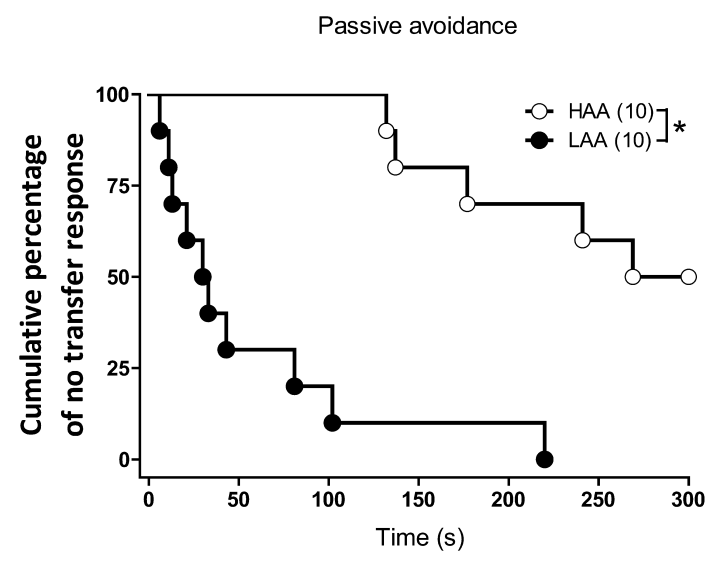

Fig. 1. Performance of male HAA (white circles, $n=10$ ) and LAA rats (black circles, $n=10$ ) in the passive avoidance task. Asterisks indicate significant differences between the groups $(P<0.05)$.

$\mathrm{m}, \mathrm{n}=10$; LAA, $12.51 \pm 0.78 \mathrm{~m}, \mathrm{n}=10$ ) (Fig. 2B). On the other hand, HAA rats spent significantly shorter amount of time in the central area than LAA rats (HAA, $2.75 \pm$ $0.79 \mathrm{~s}, \mathrm{n}=10$; LAA, $11.04 \pm 2.52 \mathrm{~s}, \mathrm{n}=10$ ) (Fig. 2C).

\section{Elevated plus maze test}

During the experiment, two HAA rats fell off of the apparatus and were excluded from the data analysis. HAA rats showed a significantly low frequency in the number of entries into open arms than LAA rats (HAA, $3.00 \pm 0.60, \mathrm{n}=8$; LAA, $5.00 \pm 0.73, \mathrm{n}=10$ ) (Fig. 3A). Additionally, HAA rats spent significantly smaller percentage of time in open arms than LAA rats (HAA, 11.31 $\pm 2.29 \%, \mathrm{n}=8$; LAA, $21.15 \pm 4.69 \%, \mathrm{n}=10$ ) (Fig. 3B).

\section{Discussion}

The present study demonstrated that selection and breeding of Hatano HAA and LAA strain rats by shuttlebox task had been properly performed with the criterion of high or low avoidance performance. The emotional characteristics of Hatano rats were further disclosed through present study.

In the present study, HAA rats showed significantly high performance as compared with LAA rats in the passive avoidance task, coinciding with the result in the shuttle-box task [1]. It is considered that they have no strain difference in foot shock sensitivity because there were no significant strain differences in avoidance, escape and freezing behaviors between them during the initial 20 out of 60 trials in the shuttle-box task [31].
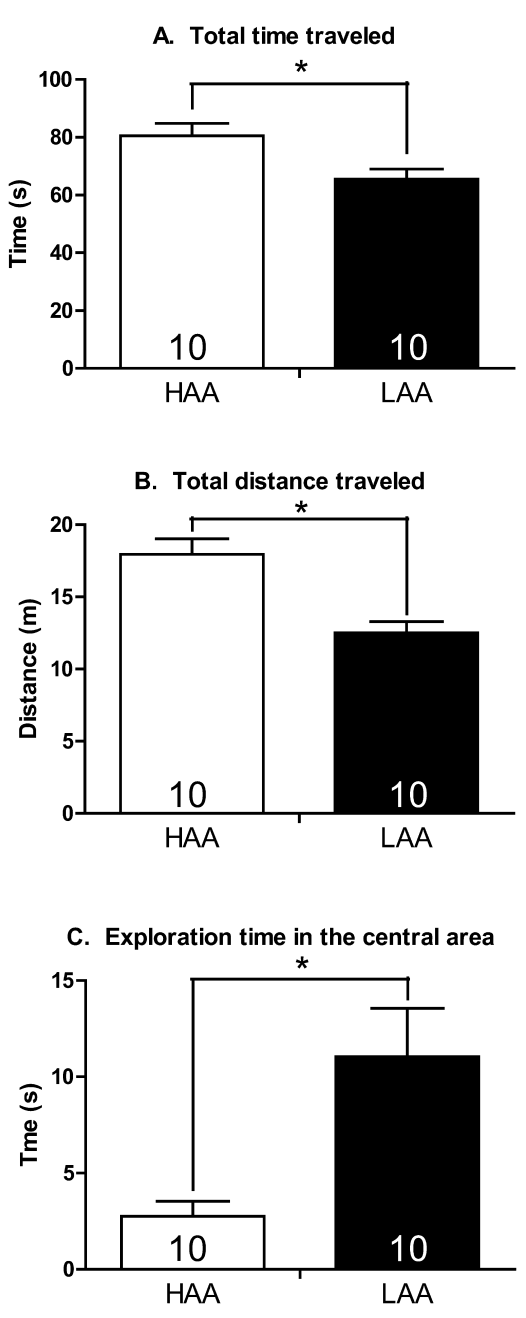

Fig. 2. Behavioral profiles in the open field test; (A) total time traveled, (B) total distance traveled, and (C) exploration time in the central area of the HAA (white bars) and LAA (black bars) males. Numerals in the bars indicate the number of rats in each group. All results are expressed as means \pm SEM and asterisks indicate significant differences between the columns $(P<0.05)$.

This indicates that they were differentiated into two-way, high or low avoidance animals in accordance with avoidance performance rather than electric shock sensitivity. By contrast, unlike Hatano rats, some other rat strains selected through avoidance performance in the shuttlebox task do not exhibit the same result in other avoidance task $[8-10,15,16]$. For instance, the Syracuse lowavoidance rat (SLA), derived from Long-Evan rats showed rapid acquisition in the passive avoidance task compared with high-avoidance rats (SHA) $[8,10]$, and 
A. Entries into open arm

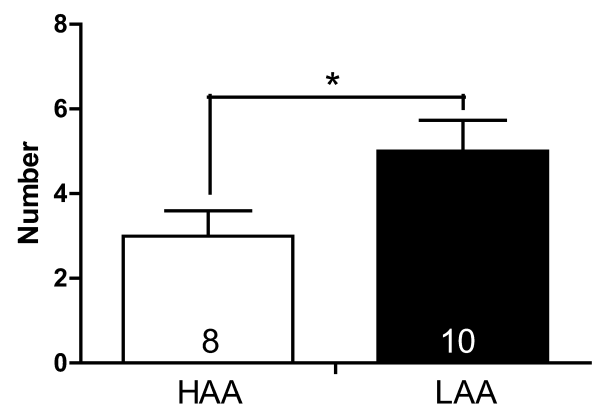

B. Percentage of time in open arms

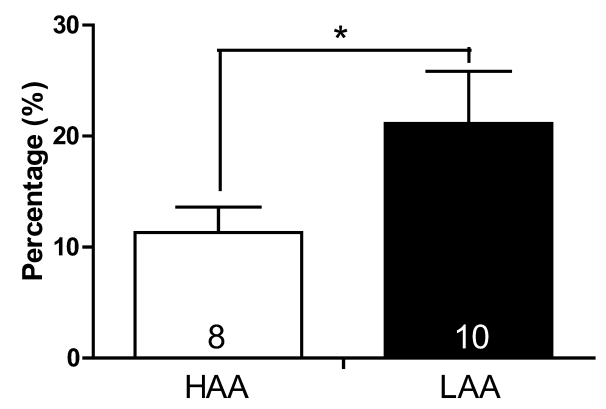

Fig. 3. Behavioral profiles in the elevated plus maze test; (A) frequency of entries into open arm and (B) percentage of time spent exploring the open arms by HAA (white bars, $n=8$ ) and LAA (black bars, $n=10$ ) males. Numerals in the bars indicate the number of rats in each group. All results are expressed as means \pm SEM and asterisks indicate significant difference between the columns $(P<0.05)$.

Roman high- (RHA) and low-avoidance (RLA) animal strains, derived from Wistar rats, do not show significant strain differences in the passive avoidance task [15]. These differences among the 3 inbred strains, including the Hatano strain, in the passive avoidance task may have occurred due to different criteria for selection in the shuttle-box task. For the Syracuse rats, 10 pretest trials were performed before the 60 trials of the shuttle-box task [7]. Firstly, they selected only animals that fled to the non-stress chamber fewer than 5 times with a shortlatency $(5.0 \mathrm{~s})$ during the pretest, and animals showing such a response fewer than 3 times during the last 5 trials of the pretest were selected for the following 60 trial session. Finally, they selected either high or low avoidance animals relative to the generation mean in the 60 trial session as SHA and SLA, respectively. In short, SHA and SLA were selected via the 60 trial session from the population selected by the pretest that did not recognize CS as aversive stress selected [7]. For the Roman rats, high and low avoidance rats were simply selected relative to the generation mean as RHA and RLA, respectively [5]. Thus, freezing animals that had learnt CS might be included in both SLA and RLA. Therefore, the behavioral difference in the passive avoidance task in Syracuse and Roman rats seems to be due to high behavioral inhibition in the low avoidance lines, rather than their low ability in avoidance learning $[8-10,15,16]$. Last but not least, it is strongly indicated that selection and breeding of the Hatano rats were properly carried out on the basis of avoidance learning in the shuttle-box.

For the secondary objective, we examined the emotionality of HAA and LAA rats by open field and elevated plus maze tests. In the present study, the time spent exploring the central area of the open field test was significantly lower in HAA than in LAA rats. Similarly, the number of open-arm entries and the percent time spent in the open arms in the elevated plus maze test were also significantly lower in HAA than in LAA rats. Exploration of the central area in the open field or open arms in the elevated plus maze is regarded as an indication of decreased anxiety-related status of the animal [6, $22,32]$. Therefore, the present results suggested that the male HAA rats are predisposed to high anxiety compared with the male LAA rats. Previous studies demonstrated that Hatano strains have clear strain differences in the functions of the hypothalamo-pituitary-adrenal (HPA) axis $[1,2,4]$, which has a pivotal role in physiologic response to stress, learning and anxiety-related status in animals [13, 20, 23, 24, 33, 34, 37, 38]. Corticotropinreleasing hormone $(\mathrm{CRH})$, arginine vasopressin (AVP) and prolactin are known as anxiety-related hormones $[18,23,25,38]$. For example, exogenous administration of CRH induces anxiety-like behaviors in rats [23]. In Hatano rats, the basal level of CRH content in the paraventricular nuclei (PVN) is significantly lower in HAA than in LAA rats; however, HAA rats showed higher emotional reactivity than LAA rats. Furthermore, the level of CRH content in the PVN showed no significant strain difference after the first session of the shuttle-box task [1]. Additionally, the level of CRH and AVP contents in the amygdala showed no strain difference before and after the first session of the shuttle-box task [1]. Central administration of prolactin engenders anxiolytic-like effects in the elevated plus maze test [38]. In Hatano rats, prolactin secretion as a stress response is signifi- 
cantly lower in HAA than in LAA rats $[2,4]$. Also, prolactin receptors, especilally long-form receptor expression in the PVN, are not altered in HAA rats but are significantly increased in LAA rats after restraint stress in water [2]. It is known that the long-form receptor is dominant to the short-form receptor, and long-form receptor expression is increased by stress in rats [38]. Also, downregulation of the long-form receptor increases anxiety-like behavior in the elevated plus maze [38]. Thus, we speculated that the strain differences in emotional reactivity in the present results might be due to the differences in endocrine stress response such as prolactin secreting ability and/or sensitivity between HAA and LAA rats, although further evidence is required.

Coping strategy, either active or passive style, is also an important factor associated with emotionality for choosing SSDRs [14, 36], and it would generate diverse behaviors. As mentioned earlier, emotionality affects the results of avoidance behavior; however, there is no coherent relationship with avoidance performance. For example, SLA and RLA rats show higher emotional reactivity, but LAA rats show lower emotional reactivity as compared with their high avoidance counterparts, respectively $[7,17,36]$. This discrepancy is explained by the concept of coping strategy. Passive coping animals with high anxiety may show freezing behavior, and active coping animals with high anxiety show avoidance/ escape behavior. Thus, an investigation into the coping style would provide further understanding of the characteristics of Hatano rats.

Further, the total time traveled and the total distance traveled in the open field test were significantly greater in HAA than in LAA rats. These results coincided with the previous report showing that the ambulation length of HAA in the open field test was greater than that of LAA rats at 5 weeks old [29]. In Hatano rats, it is known that HAA rats show higher activity in wheel running than LAA rats, and it was not altered by cross-fostering [28, 29], although the Hatano strain was not selected by the criterion of spontaneous activity [30]. Thus, it is considered that this strain difference is caused by the difference in locomotor activity between HAA and LAA rats.

In summary, the present study clearly demonstrated the high and low avoidance performances of HAA and LAA rats respectively in the different avoidance tasks. The present results suggest that the selection and breeding of Hatano strain rats were properly performed with the criterion of avoidance learning by the shuttle-box task, although other avoidance learning paradigms using non-electric stimuli like predator odor or something else are required to disclose their whole aspects in regard to avoidance performance. Additionally, the HAA strain exhibits higher anxiety-like behaviors compared with rats of the LAA strain. We assume that this strain difference is partly due to the difference in endocrine stress response to a novel environment. Thus, anxiety and its endocrine response, the critical factors for species' survival and conservation, might be associated with acquisition of avoidance learning ability.

\section{Acknowledgments}

The authors are grateful to Itsumi Ozawa, Reena Niwa and Chisato Hashikura for their research assistance. This work was supported by Research on Risk of Chemical Substances, Health and Laboratory Sciences Research Grants, Ministry of Health, Labour and Welfare, Japan, and was also partially supported by a grant for Research and Development Projects for Application in Promoting New Policy of Agriculture, Forestry and Fisheries, Japan.

\section{References}

1. Akieda-Asai, S., Ohta, R., Shirota, M., Jaroenporn, S., Watanabe, G., and Taya, K. 2011. Endocrinological differences between hatano high- and low-avoidance rats during early two-way avoidance acquisition. Exp. Anim. 60: 509-516. [Medline] [CrossRef]

2. Asai, S., Ohta, R., Fujikawa, T., Sakai, R.R., Shirota, M., Ogata, M., Watanabe, G., and Taya, K. 2006. Gastric ulceration and expression of prolactin receptor in the brain in Hatano high- and low-avoidance rats. Endocrine 30: 161-166. [Medline] [CrossRef]

3. Asai, S., Ohta, R., Shirota, M., Tohei, A., Watanabe, G., and Taya, K. 2004. Endocrinological responses during suckling in Hatano high- and low-avoidance rats. J. Endocrinol. 182: 267-272. [Medline] [CrossRef]

4. Asai, S., Ohta, R., Shirota, M., Watanabe, G., and Taya, K. 2004. Differential responses of the hypothalamo-pituitaryadrenocortical axis to acute restraint stress in Hatano highand low-avoidance rats. J. Endocrinol. 181: 515-520. [Medline] [CrossRef]

5. Bignami, G. 1965. Selection for high rates and low rates of avoidance conditioning in the rat. Anim. Behav. 13: 221-227. [Medline] [CrossRef]

6. Blizard, D.A. and Adams, N. 2002. The Maudsley Reactive and Nonreactive strains: a new perspective. Behav. Genet. 32: 277-299. [Medline] [CrossRef]

7. Brush, F.R. 2003. Selection for differences in avoidance learning: the Syracuse strains differ in anxiety, not learning ability. Behav. Genet. 33: 677-696. [Medline] [CrossRef] 
8. Brush, F.R., Del Paine, S.N., Pellegrino, L.J., Rykaszewski, I.M., Dess, N.K., and Collins, P.Y. 1988. CER suppression, passive-avoidance learning, and stress-induced suppression of drinking in the Syracuse high- and low-avoidance strains of rats (Rattus norvegicus). J. Comp. Psychol. 102: 337-349. [Medline] [CrossRef]

9. Brush, F.R., Froehlich, J.C., and Sakellaris, P.C. 1979. Genetic selection for avoidance behavior in the rat. Behav. Genet. 9: 309-316. [Medline] [CrossRef]

10. Brush, F.R., Gendron, C.M., and Isaacson, M.D. 1999. A selective genetic analysis of the Syracuse high- and low-avoidance (SHA/Bru and SLA/Bru) strains of rats (Rattus norvegicus). Behav. Brain Res. 106: 1-11. [Medline] [CrossRef]

11. Carrasco, J., Marquez, C., Nadal, R., Tobena, A., FernandezTeruel, A., and Armario, A. 2008. Characterization of central and peripheral components of the hypothalamus-pituitaryadrenal axis in the inbred Roman rat strains. Psychoneuroendocrinology 33: 437-445. [Medline] [CrossRef]

12. Castanon, N., Dulluc, J., le Moal, M., and Mormede, P. 1992. Prolactin as a link between behavioral and immune differences between the Roman rat lines. Physiol. Behav. 51: 1235-1241. [Medline] [CrossRef]

13. Catalani, A., Alema, G.S., Cinque, C., Zuena, A.R., and Casolini, P. 2011. Maternal corticosterone effects on hypothalamus-pituitary-adrenal axis regulation and behavior of the offspring in rodents. Neurosci. Biobehav. Rev. 35: 15021517. [Medline] [CrossRef]

14. Crawford, M. and Masterson, F.A. 1982. Species-specific defense reactions and avoidance learning. An evaluative review. Pavlov. J. Biol. Sci. 17: 204-214. [Medline]

15. Driscoll, P. and Bättig, K. 1982. Behavioral, emotional and neurochemical profiles of rat selected for extreme differences in active, two-way avoidance performance. pp. 95-123. In: Genetics of the Brain (Lieblich, I. ed.), Elsevier, Amsterdam.

16. Driscoll, P., Escorihuela, R.M., Fernandez-Teruel, A., Giorgi, O., Schwegler, H., Steimer, T., Wiersma, A., Corda, M.G., Flint, J., Koolhaas, J.M., Langhans, W., Schulz, P.E., Siegel, J., and Tobena, A. 1998. Genetic selection and differential stress responses. The Roman lines/strains of rats. Ann. N. Y. Acad. Sci. 851: 501-510. [Medline] [CrossRef]

17. Escorihuela, R.M., Fernandez-Teruel, A., Gil, L., Aguilar, R., Tobena, A., and Driscoll, P. 1999. Inbred Roman highand low-avoidance rats: differences in anxiety, novelty-seeking, and shuttlebox behaviors. Physiol. Behav. 67: 19-26. [Medline] [CrossRef]

18. Gold, P.E. and Van Buskirk, R. 1976. Enhancement and impairment of memory processes with post-trial injections of adrenocorticotrophic hormone. Behav. Biol. 16: 387-400. [Medline] [CrossRef]

19. Imhof, J.T., Coelho, Z.M., Schmitt, M.L., Morato, G.S., and Carobrez, A.P. 1993. Influence of gender and age on performance of rats in the elevated plus maze apparatus. Behav. Brain Res. 56: 177-180. [Medline] [CrossRef]

20. Jaferi, A. and Bhatnagar, S. 2007. Corticotropin-releasing hormone receptors in the medial prefrontal cortex regulate hypothalamic-pituitary-adrenal activity and anxiety-related behavior regardless of prior stress experience. Brain Res.
1186: 212-223. [Medline] [CrossRef]

21. Jaroenporn, S., Nagaoka, K., Ohta, R., Watanabe, G., and Taya, K. 2007. Direct effects of prolactin on adrenal steroid release in male Hatano high-avoidance (HAA) rats may be mediated through Janus kinase 2 (Jak2) activity. J. Reprod. Dev. 53: 887-893. [Medline] [CrossRef]

22. Kawaguchi, M., Irie, K., Morohoshi, K., Watanabe, G., Taya, K., Morita, M., Kondo, Y., Imai, H., and Himi, T. 2009. Maternal isobutyl-paraben exposure alters anxiety and passive avoidance test performance in adult male rats. Neurosci. Res. 65: 136-140. [Medline] [CrossRef]

23. Kishimoto, T., Radulovic, J., Radulovic, M., Lin, C.R., Schrick, C., Hooshmand, F., Hermanson, O., Rosenfeld, M.G., and Spiess, J. 2000. Deletion of crhr2 reveals an anxiolytic role for corticotropin-releasing hormone receptor-2. Nat. Genet. 24: 415-419. [Medline] [CrossRef]

24. Kozlovsky, N., Zohar, J., Kaplan, Z., and Cohen, H. 2012. Microinfusion of a CRH receptor 1 antisense oligodeoxynucleotide into the dorsal hippocampus attenuates stress responses at specific times following stress exposure. $J$. Neuroendocrinol. 24: 489-503. [CrossRef]

25. Landgraf, R., Kessler, M.S., Bunck, M., Murgatroyd, C., Spengler, D., Zimbelmann, M., Nussbaumer, M., Czibere, L., Turck, C.W., Singewald, N., Rujescu, D., and Frank, E. 2007. Candidate genes of anxiety-related behavior in $\mathrm{HAB} /$ LAB rats and mice: focus on vasopressin and glyoxalase-I. Neurosci. Biobehav. Rev. 31: 89-102. [Medline] [CrossRef]

26. Masur, J., Schutz, M.T., and Boerngen, R. 1980. Gender differences in open-field behavior as a function of age. Dev. Psychobiol. 13: 107-110. [Medline] [CrossRef]

27. McNamara, M.C., Benignus, G., Benignus, V.A., and Miller, A.T. Jr. 1977. Active and passive avoidance in rats as a function of age. Exp. Aging Res. 3: 3-16. [Medline] [CrossRef]

28. Ohta, R., Matsumoto, A., Nagao, T., and Mizutani, M. 1998. Comparative study of behavioral development between high and low shuttlebox avoidance rats. Physiol. Behav. 63: 545551. [Medline] [CrossRef]

29. Ohta, R., Matsumoto, A., Sato, M., Shirota, M., Nagao, T., Tohei, A., and Taya, K. 2000. Postnatal behavior in hatano high- and low-avoidance rats following prenatal exposure to low-dose methylazoxymethanol. Neurotoxicol. Teratol. 22: 405-413. [Medline] [CrossRef]

30. Ohta, R., Matumoto, A., Hashimoto, Y., Nagao, T., and Mizutani, M. 1995. Behavioral characteristics of rats selectively bred for high and low avoidance shuttlebox response. Cong. Anom. 35: 223-229.

31. Ohta, R., Shirota, M., Adachi, T., Tohei, A., and Taya, K. 1999. Plasma ACTH levels during early, two-way avoidance acquisition in high- and low-avoidance rats (Hatano strains). Behav. Genet. 29: 137-144. [Medline] [CrossRef]

32. Pellow, S., Chopin, P., File, S.E., and Briley, M. 1985. Validation of open:closed arm entries in an elevated plus-maze as a measure of anxiety in the rat. J. Neurosci. Methods 14: 149-167. [Medline] [CrossRef]

33. Refojo, D., Schweizer, M., Kuehne, C., Ehrenberg, S., Thoeringer, C., Vogl, A.M., Dedic, N., Schumacher, M., von Wolff, G., Avrabos, C., Touma, C., Engblom, D., Schutz, G., Nave, K.A., Eder, M., Wotjak, C.T., Sillaber, I., Hols- 
boer, F., Wurst, W., and Deussing, J.M. 2011. Glutamatergic and dopaminergic neurons mediate anxiogenic and anxiolytic effects of CRHR1. Science 333: 1903-1907. [Medline] [CrossRef]

34. Shors, T.J. 2006. Stressful experience and learning across the lifespan. Annu. Rev. Psychol. 57: 55-85. [Medline] [CrossRef]

35. Steimer, T. and Driscoll, P. 2003. Divergent stress responses and coping styles in psychogenetically selected Roman high(RHA) and low-(RLA) avoidance rats: behavioural, neuroendocrine and developmental aspects. Stress 6: 87-100. [Medline] [CrossRef]

36. Steimer, T., la Fleur, S., and Schulz, P.E. 1997. Neuroendo- crine correlates of emotional reactivity and coping in male rats from the Roman high (RHA/Verh)- and low (RLA/ Verh)-avoidance lines. Behav. Genet. 27: 503-512. [Medline] [CrossRef]

37. Stenzel-Poore, M.P., Heinrichs, S.C., Rivest, S., Koob, G.F., and Vale, W.W. 1994. Overproduction of corticotropin-releasing factor in transgenic mice: a genetic model of anxiogenic behavior. J. Neurosci. 14: 2579-2584. [Medline]

38. Torner, L., Toschi, N., Pohlinger, A., Landgraf, R., and Neumann, I.D. 2001. Anxiolytic and anti-stress effects of brain prolactin: improved efficacy of antisense targeting of the prolactin receptor by molecular modeling. J. Neurosci. 21: 3207-3214. [Medline] 